\title{
Article \\ The Impact of Different Periods of Walking Experience on Kinematic Gait Parameters in Toddlers
}

\author{
Marta Gimunová ${ }^{1, * \mathbb{D}}$, Martin Sebera ${ }^{1} \mathbb{D}$, Michal Bozděch $^{1} \mathbb{D}$, Kateřina Kolářová ${ }^{2}$, Tomáš Vodička ${ }^{1} \mathbb{D}$ \\ and Martin Zvonař 1 \\ 1 Department of Kinesiology, Faculty of Sports Studies, Masaryk University, 62500 Brno, Czech Republic; \\ sebera@fsps.muni.cz (M.S.); michal.bozdech@fsps.muni.cz (M.B.); tvodicka@fsps.muni.cz (T.V.); \\ zvonar@fsps.muni.cz (M.Z.) \\ 2 University Sport Centre, Faculty of Sports Studies, Masaryk University, 62500 Brno, Czech Republic; \\ katerina.kolarova@fsps.muni.cz \\ * Correspondence: gimunova@fsps.muni.cz; Tel.: +420-54949-8398
}

check for updates

Citation: Gimunová, M.; Sebera, M.; Bozděch, M.; Kolářová, K.; Vodička, T.; Zvonař, M. The Impact of Different Periods of Walking Experience on Kinematic Gait Parameters in Toddlers. Int. J. Environ. Res. Public Health 2022, 19, 58. https://doi.org/10.3390/ ijerph19010058

Academic Editor: Chiara Ionio

Received: 3 November 2021

Accepted: 19 December 2021

Published: 22 December 2021

Publisher's Note: MDPI stays neutral with regard to jurisdictional claims in published maps and institutional affiliations.

Copyright: (C) 2021 by the authors. Licensee MDPI, Basel, Switzerland. This article is an open access article distributed under the terms and conditions of the Creative Commons Attribution (CC BY) license (https:// creativecommons.org/licenses/by/ $4.0 /)$.

\begin{abstract}
This study aimed to analyse the kinematic differences in gait between three groups of toddlers who differed in their weeks of independent walking (IW) experience, but not in anthropometrical characteristics, to determine the relationship between walking experience without the side effect of morphological differences on gait parameters. Twenty-six toddlers participated in this study. Depending on the week of their IW, toddlers were divided into three groups: Group 1 (1-5 weeks of IW), Group 2 (6-10 weeks of IW), and Group 3 (11-15 weeks of IW). Each toddler walked barefooted over a 2-m long pathway, and 3D kinematic data were obtained. A decrease in the upper limb position, hip flexion, and step width, i.e., changes towards the adult gait pattern, were observed in Group 3. Less experienced walkers exhibited a wider step width despite no statistically significant difference in body mass and height between groups. Results of this study show no statistically significant difference in step length between groups, suggesting that step length is more related to height than to the walking experience. The increased step length in more experienced walkers reported in previous studies may therefore be a result of different heights and not walking experience.
\end{abstract}

Keywords: gait; children; motor development; temporal-spatial parameters; kinematic analysis

\section{Introduction}

The development of walking in toddlers is an important kinematic milestone. Walking patterns can vary widely amongst toddlers and are characterised by unique biomechanical strategies [1]. Walking alone was reported to have the widest variety in the age of achievement compared to other gross motor developmental milestones in babies and toddlers [2].

Toddlers perform their first unsupported steps between approximately 8.2 to 17.6 months of age (estimated 1st and 99th percentile) [2,3] and are gradually refined with practice and maturity [2]. To be able to walk, the toddler must acquire postural stability control with respect to gravity. Pre-walking toddlers at about 10 months of age can maintain the static equilibrium; however, they perform a greater centre of pressure sway compared to adults [4]. This greater disequilibrium, measured by the distance of the centre of mass to the centre of pressure, was observed in toddlers at the onset of walking [5]. Furthermore, toddlers must acquire dynamic control of the body to perform forward motion. The swing phase, when only one leg supports the whole body, is the most challenging problem when learning to walk [6-8]. Walking maturation consists of two phases. During the first phase, up to six months after independent walking (IW), the dynamic equilibrium and trunk stabilisation during gait improves, the second phase (up to 7 years) is characterised by a more precise adjustment of the gait parameters $[9,10]$.

The early stage of IW is characterised by large individual variability in walking maturation strategies. There are some typical patterns in this variation within this early 
stage of walking. In novice walkers with less than 22 weeks of walking experience, three different patterns of foot contact were described: (i) heel strike (characterised by the initial contact of heel and then the heel to toe roll-over process continues), (ii) flatfoot contact (characterised by simultaneous contact of the forefoot and heel and subsequent heel to toe roll-over), and (iii) forefoot contact (characterised by the initial contact of metatarsals, then the midfoot and heel are placed on the ground and subsequent heel to toe roll-over follows) [11,12]. In toddlers, a wide base of support, asymmetrical foot rotation, and high foot lift during the swing phase of the step cycle were observed compared to the adult gait $[13,14]$.

The classic pendulum mechanism is not yet implemented in novice walkers [14], it develops after a few months of walking experience, and it is evident in improved walking patterns [15] by adopting more effective solutions [16]. Still, little is known about changes in the gait pattern in the early phases of IW in relation to the walking experience. Understanding gait development changes in this period can be essential for the explanation of different solutions of IW.

Previous studies focused on the early stages of walking without considering the effect of different body masses, heights, and the age of their participants. It can be hypothesised that some of the changes associated with walking experience in these studies might instead reflect the body mass or height changes. In this study, the kinematic differences in gait between three groups of toddlers who, despite no statistical difference in age (as the inclusion criteria consisted of age as closed to 17 months as possible), body mass, and height, differed in their weeks of walking experience were analysed. The purpose of this study was to assess the differences in kinematic gait parameters related to walking practice to gain a better understanding of the ontogenetic development of human walking.

\section{Materials and Methods}

\subsection{Participants}

Originally, 30 healthy toddlers participated in this study; however, 4 toddlers from Group 1 (one to five weeks of IW) were not able to cooperate during the data collection. Data of 26 healthy toddlers of a similar age, height, and body mass were included in this study. Inclusion criteria consisted of typical development, an age as close to 17 months as possible, and gestational age of more than 37 weeks. The exclusion criteria consisted of any foot or lower limb deformities and any significant previous foot or lower limb injuries or operations. Depending on the week of their walking experience defined by the first five consecutive steps without any support reported by parents, participants were divided into three groups: Group $1(n=6)$ had one to five weeks of walking experience, Group $2(n=10)$ had six to ten weeks of walking experience, and Group $3(n=10)$ had eleven to fifteen weeks of walking experience. Informed consent was provided by legal representatives of the toddlers prior to measurement. This study was approved by the local Research Ethics Committee. The measurement was performed in accordance with the ethical standards of the Helsinki Declaration.

\subsection{Procedures and Equipment}

Each participant was encouraged to walk several times to obtain five attempts with no unexpected change of direction or fall, barefooted over a 2-m long pathway towards a parent or a toy at a self-selected speed, wearing a bodysuit or a diaper as the clothes were observed to modify the walking pattern in toddlers [17]. One gait cycle of each participant during the third attempt, if no unexpected change of direction or fall occurred, was used for further analysis.

The gait 3D kinematic data were obtained using seven cameras (Basler A602fc, Unterschleißheim, Germany) from the Simi Motion System, filmed at $100 \mathrm{~Hz}$. The camera placement with respect to the walking line is shown in Figure 1. Selected anthropometric points were tracked using the Simi Motion Software: left and right acromiale, iliospinale 
anterius, tibiale laterale, malleolus lateralis, and stylion. The beginning of the gait cycle was determined by the first foot contact with the ground.

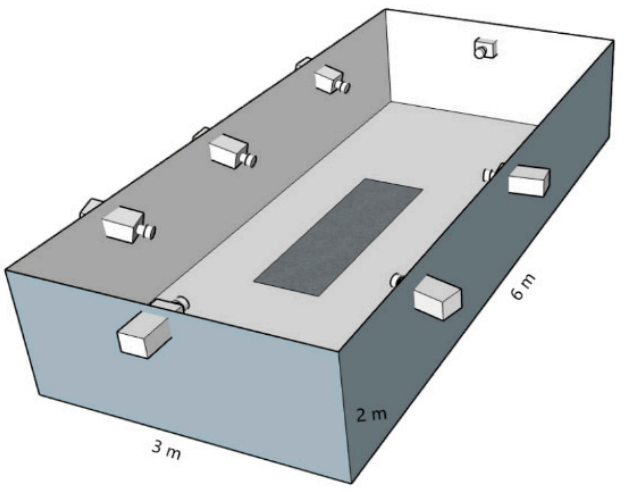

Figure 1. Camera placement during the 3D kinematic data collection.

The following parameters were used for further analysis. For the angular parameters of the hip and knee joint range of motion (ROM), the maximum and minimum for the right and left sides were analysed. The maximal angle was analysed for upper limb position, for anterio-posterior and medio-lateral trunk lean, the ROM was analysed.

- $\quad$ stride time (s): time between foot contact and subsequent foot contact of the same foot.

- $\quad$ step length $(\mathrm{m})$ : distance between consecutive steps.

- $\quad$ step width $(\mathrm{m})$ : distance between the left and right malleolus lateralis (ankle spread).

- $\quad$ hip joint angle $\left({ }^{\circ}\right)$ : angle between the point acromiale, iliospinale anterius, and tibiale laterale in the sagittal plane during the gait cycle.

- $\quad$ knee joint angle $\left({ }^{\circ}\right)$ : angle between the point iliospinale anterius, tibiale laterale, and malleolus lateralis in the sagittal plane during the gait cycle.

- $\quad$ upper limb position $\left(^{\circ}\right)$ : angle between the point iliospinale anterius, acromiale, and stylion during the gait cycle.

- $\quad$ anterio-posterior trunk lean $\left(^{\circ}\right)$ : angle between the point acromiale, iliospinale anterius, and sagittal plane during the gait cycle.

- medio-lateral trunk lean $\left({ }^{\circ}\right)$ : angle between the point acromiale, iliospinale anterius, and frontal plane during the gait cycle.

\subsection{Statistical Analysis}

Most of the variables did not meet the assumptions of normal distribution and homogeneity of variance, verified by a test of normality (Shapiro-Wilk test) and Levene test of homogeneity of variances. Therefore, a Kruskal-Wallis test and multiple comparisons $p$ values were used to compare the differences between groups together with eta ${ }^{2}$ (effect size for Kruskal-Wallis test, eta ${ }^{2}=(\mathrm{H}-\mathrm{k}+1) /(\mathrm{n}-\mathrm{k})$; where $\mathrm{H}$ is the value obtained in the Kruskal-Wallis test; $\mathrm{k}$ is the number of groups; $\mathrm{n}$ is the total number of observations). The thresholds values according to the Cohen [18] rules of thumb were set as small (eta $\left.{ }^{2}=0.01\right)$, moderate (eta $\left.{ }^{2}=0.06\right)$, or large (eta ${ }^{2}=0.14$ ) effect.

$p<0.05$ was considered statistically significant. The statistics were obtained using the Statistica TIBCO Software Inc. (Palo Alto, CA, USA), version 13.5.

\section{Results}

A Kruskal-Wallis test and multiple comparisons of $p$ values were used to compare the differences between Group 1, 2, and 3. No statistically significant differences between groups were observed in body mass $(p=0.379)$, height $(p=0.981)$, age $(p=0.211)$, and BMI $(p=0.178)$. The groups' characteristics are shown in Table 1 . 
Table 1. Groups' characteristics.

\begin{tabular}{cccccccc}
\hline & & Body Mass (kg) & Body Height $\mathbf{( c m )}$ & Age (Months) & BMI & $\begin{array}{c}\text { Walking Experience } \\
\text { (Weeks) }\end{array}$ & Gender \\
\hline Group 1 & Mean & 9.90 & 78.50 & 16.92 & 16.07 & 3.67 & female $n=3$ \\
& SD & 1.09 & 4.97 & 2.57 & 1.08 & 1.75 & male $n=3$ \\
Group 2 & Mean & 10.15 & 77.95 & 15.79 & 16.75 & 7.80 & female $n=5$ \\
& SD & 0.99 & 3.13 & 1.70 & 1.88 & 1.14 & male $n=5$ \\
Group 3 & Mean & 10.66 & 77.70 & 17.07 & 17.75 & 12.30 & female $n=5$ \\
& SD & 1.29 & 5.33 & 1.98 & 2.29 & 1.57 & male $n=5$ \\
& $p$ & 0.379 & 0.981 & 0.211 & 0.178 & & \\
\hline
\end{tabular}
shown

In Table 2, the Means and SD of the analysed gait parameters for each group are

Table 2. Mean and SD of analysed parameters for Groups 1, 2, and 3.

\begin{tabular}{|c|c|c|c|c|c|c|c|c|}
\hline & & \multicolumn{2}{|c|}{ Group 1} & \multicolumn{2}{|c|}{ Group 2} & \multicolumn{2}{|c|}{ Group 3} & \multirow{2}{*}{$p$} \\
\hline & & Mean & SD & Mean & SD & Mean & SD & \\
\hline \multirow{3}{*}{ Temporo-spatial parameters } & Stride time (s) & 1.02 & 0.17 & 1.05 & 0.15 & 1.05 & 0.19 & 0.878 \\
\hline & Step length $(\mathrm{cm})$ & 0.18 & 0.03 & 0.18 & 0.05 & 0.18 & 0.05 & 0.704 \\
\hline & Step width $(\mathrm{cm})$ & 0.19 & 0.04 & 0.15 & 0.05 & 0.12 & 0.02 & $0.005^{\mathrm{A}}$ \\
\hline \multirow{3}{*}{ Hip joint angle, left } & $\operatorname{RoM}\left(^{\circ}\right)$ & 42.53 & 10.15 & 33.22 & 7.89 & 29.11 & 7.70 & $0.037^{\mathrm{A}}$ \\
\hline & $\operatorname{Min}\left({ }^{\circ}\right)$ & 131.50 & 10.64 & 141.99 & 8.93 & 147.43 & 9.76 & $0.030^{\mathrm{A}}$ \\
\hline & $\operatorname{Max}\left({ }^{\circ}\right)$ & 174.04 & 2.88 & 175.20 & 8.46 & 176.54 & 5.16 & 0.144 \\
\hline \multirow{3}{*}{ Hip joint angle, right } & $\operatorname{RoM}\left({ }^{\circ}\right)$ & 40.46 & 7.91 & 32.28 & 8.59 & 33.35 & 8.76 & 0.206 \\
\hline & $\operatorname{Min}\left({ }^{\circ}\right)$ & 134.19 & 12.72 & 142.42 & 8.72 & 145.05 & 8.98 & 0.222 \\
\hline & $\operatorname{Max}\left({ }^{\circ}\right)$ & 174.65 & 8.73 & 174.70 & 5.54 & 178.39 & 1.22 & 0.285 \\
\hline \multirow{3}{*}{ Knee joint angle, left } & $\operatorname{RoM}\left({ }^{\circ}\right)$ & 71.14 & 10.67 & 63.58 & 11.75 & 68.56 & 8.28 & 0.413 \\
\hline & $\operatorname{Min}\left({ }^{\circ}\right)$ & 103.99 & 9.08 & 107.94 & 8.00 & 105.56 & 10.85 & 0.781 \\
\hline & $\operatorname{Max}\left({ }^{\circ}\right)$ & 175.13 & 3.91 & 171.52 & 8.08 & 174.11 & 8.03 & 0.206 \\
\hline \multirow{3}{*}{ Knee joint angle, right } & RoM v & 67.40 & 12.52 & 63.78 & 7.21 & 71.05 & 15.52 & 0.472 \\
\hline & $\operatorname{Min}\left(^{\circ}\right)$ & 106.91 & 12.05 & 108.58 & 3.37 & 104.57 & 14.78 & 0.182 \\
\hline & $\operatorname{Max}\left({ }^{\circ}\right)$ & 174.31 & 5.41 & 172.36 & 7.26 & 175.61 & 4.32 & 0.627 \\
\hline Upper limb position, left & $\operatorname{Max}\left({ }^{\circ}\right)$ & 78.30 & 23.43 & 61.08 & 21.81 & 48.72 & 10.79 & $0.026^{\mathrm{A}}$ \\
\hline Upper limb position, right & $\operatorname{Max}\left({ }^{\circ}\right)$ & 86.59 & 26.54 & 65.66 & 22.61 & 46.94 & 17.40 & $0.008^{\mathrm{A}}$ \\
\hline Anterio-posterior trunk lean & $\operatorname{RoM}\left(^{\circ}\right)$ & 8.46 & 4.30 & 7.64 & 2.07 & 5.86 & 2.54 & 0.096 \\
\hline Medio-lateral trunk lean & $\operatorname{RoM}\left(^{\circ}\right)$ & 6.33 & 2.56 & 7.06 & 2.09 & 6.31 & 2.55 & 0.727 \\
\hline
\end{tabular}

RoM-Range of Motion, ${ }^{\text {A }}$ statistically significant difference between Group 1 and Group 3.

When comparing groups, a statistically significant difference was observed in the minimum left hip joint angle between Groups 1 and $3\left(p=0.030\right.$ eta $\left.^{2}=0.218\right)$, where an increase in this angle was observed in more experienced walkers. Statistically, significant differences were also observed in the left and right upper limb positions between Groups 1 and $3\left(p=0.026\right.$, eta ${ }^{2}=0.230 ; p=0.008$, eta ${ }^{2}=0.331$, respectively), Group 1 demonstrated a more upward position (the so-called high guard position) of the upper limb. Step width statistically differed between Groups 1 and $3\left(p=0.005\right.$, eta $\left.{ }^{2}=0.369\right)$, where less experienced walkers exhibited wider step width. Differences in other parameters did not reach statistical significance. Group 2 did not differ with a statistical significance from Group 1 and Group 3.

\section{Discussion}

The aim of this study was to analyse the kinematic differences in gait between three groups of toddlers who differed in their weeks of experience with IW but not in their age, height, or body mass. Knowledge regarding the relationship between the walking 
experience without the side effect of body mass, height, and age on gait parameters is limited. Most of the previous studies analysed the early stages of walking in participants of different ages, heights, and body masses $[15,19,20]$. In a previous study by Van Dam et al. [21], it was suggested that the walking pattern in toddlers is significantly related to the morphology of the head and pelvis. On the other hand, in a previous study by Kingsnorth and Schmuckler [22], walking experience was the parameter most strongly related to the ability to cross a barrier, compared to body size or age.

A decrease in the left and right upper limb position between Group 1 and Group 3 was observed in this study, where Group 1 performed a more upward position (so-called high guard position) of the upper limb. A similar finding was reported in previous studies by Kubo and Ulrich [20] and Ledebt [19], who described the lowering of the arm position and then movements in the shoulder and elbow joints when the postural stability of the toddler during the gait becomes more stable. When the first steps are performed, the arm movement could challenge the stable posture during walking [19].

In adults, step width was observed to be affected mainly by gender [23] and body mass [24]. Similarly to the studies by Ledebt [19] and Ivanenko et al. [14], in this study, a statistically significant difference was observed in the step width between Group 1 and Group 3. Less experienced walkers exhibited a wider step width despite no statistically significant difference in body mass and height between groups. In addition, in a previous study, the walking experience was found to affect the step width more than the body length [21]. Additionally, a strong relationship was observed between narrowing step width and the decrease of arm guard posture [19], similarly to the observations of this study. The narrow step width is an advantage for the toddler as it reduces the metabolic cost of walking [21].

In previous studies, step length was reported to increase in more experienced walkers $[25,26]$. Results of this study show no statistically significant difference in step length between groups. In a study by Van Dam et al. [21], a stronger correlation of step length with body length than with the walking experience was observed. The increased step length in more experienced walkers reported in previous studies may therefore be a result of different heights and not the walking experience.

A statistically significant decrease in the left hip joint flexion was observed in this study in Group 3 compared to Group 1. The decrease in this angle was observed in more experienced walkers. To enhance postural stability when walking, hip extension, during which the hip remains slightly flexed, dominates during gait in toddlers. In a previous study comparing the gait of toddlers and adults, the hip flexion in adults was smaller [27], similar to the most experienced group of walkers in this study.

The limitation of this study is the small number of participants and their division into groups 1,2, and 3 by one to five, six to ten, and eleven to fifteen weeks of walking experience and not by months of walking experience as both beginners and experienced walkers were desired to be of the same chronological age. Compared with the normal variation in age of walking alone milestone achievement, all participants started their walking relatively late; approximately 80, 90, and 97 percentiles for Group 1, Group 2, and Group 3, respectively [2]. This probably reflects the different definition of the first unsupported steps (defined in this study as five consecutive steps without any support) or the cultural differences in the caretaking environment on the infants' motor development [28]. Future studies focusing on the effect of the child development rate, e.g., through the time of achieving the gross motor developmental milestones such as standing alone or walking alone, and kinematic and dynamic gait parameters in toddlers will bring a more detailed insight into gait maturation.

\section{Conclusions}

To conclude, walking experience seems to be the main factor in gait parameter changes. A decrease in left and right upper limb position, hip flexion, and step width, i.e., changes towards the adult gait pattern, between the least (Group 1, one to five weeks of IW) and the most experienced group (Group 3, eleven to fifteen weeks of IW) of novice walkers was 
observed despite no statistically significant difference in their age, body mass or height between the groups. Toddlers with the middle walking experience (Group 2, six to ten weeks of IW) did not express a statistically significant difference from Group 1 and Group 3.

Author Contributions: Conceptualization, M.G.; methodology, M.G. and T.V.; formal analysis, M.S. and M.B.; writing-original draft preparation, M.G. and K.K.; writing-review and editing, M.G. and M.Z.; supervision, M.Z. and M.G.; funding acquisition, M.Z. All authors have read and agreed to the published version of the manuscript.

Funding: This research was performed at the Masaryk University as part of the project number MUNI/A/1196/2017 with the support of the Specific University Research Grant, as provided by the Ministry of Education, Youth and Sports of the Czech Republic in the year 2017 and as a part of the project number TJ02000059 with the support of the Technology Agency of the Czech Republic in years 2019-2021.

Institutional Review Board Statement: The study was conducted according to the guidelines of the Declaration of Helsinki and approved by the Research Ethics Committee Masaryk University (EKV-2019-032, 2 September 2019).

Informed Consent Statement: Informed consent was obtained from all subjects involved in the study.

Data Availability Statement: The data presented in this study are available upon request from the corresponding author. The data are not publicly available due to ethical restrictions.

Conflicts of Interest: The authors declare no conflict of interest.

\section{References}

1. Williams, J.H. Relative age effect in youth soccer: Analysis of the FIFA U17 World Cup competition. Scand. J. Med. Sci. Sport. 2010, 20, 502-508. [CrossRef] [PubMed]

2. WHO Multicentre Growth Reference Study Group. WHO Motor Development Study: Windows of achievement for six gross motor development milestones. Acta. Paediatr. Suppl. 2006, 450, 86-95. [CrossRef]

3. Yaguramaki, N.; Kimura, T. Acquirement of stability and mobility in infant gait. Gait Posture 2002, 16, 69-77. [CrossRef]

4. Chen, L.C.; Metcalfe, J.S.; Chang, T.Y.; Jeka, J.J.; Clark, J.E. The development of infant upright posture: Sway less or sway differently? Exp. Brain Res. 2008, 186, 293-303. [CrossRef] [PubMed]

5. Bril, B.; Dupuy, L.; Dietrich, G.; Corbetta, D. Learning to tune the antero-posterior propulsive forces during walking: A necessary skill for mastering upright locomotion in toddlers. Exp. Brain Res. 2015, 233, 2903-2912. [CrossRef]

6. Assaiante, C.; Thomachot, B.; Aurenty, R. Hip stabilization and lateral balance control in toddlers during the first four months of autonomous walking. Neuroreport 1993, 4, 875-879. [CrossRef]

7. Assaiante, C.; Thomachot, B.; Aurenty, R.; Amblard, B. Organization of lateral balance control in toddlers during the first year of independent walking. J. Mot. Behav. 1998, 30, 114-129. [CrossRef] [PubMed]

8. Cheron, G.; Bouillot, E.; Dan, B.; Bengoetxea, A.; Draye, J.P.; Lacquaniti, F. Development of a kinematic coordination pattern in toddler locomotion: Planar covariation. Exp. Brain Res. 2001, 137, 455-466. [CrossRef]

9. Cioni, G.; Milianti, B.; Paolicellia, P.; Sicola, E.; Boldrinib, A.; Ferrari, A. Differences and variations in the patterns of early independent walking. Early Hum. Dev. 1993, 35, 193-205. [CrossRef]

10. Bril, B.; Ledebt, A. Head coordination as a means to assist sensory integration in learning to walk. Neurosci. Biobehav. Rev. 1998, 22, 555-563. [CrossRef]

11. Hallemans, A.; D'Août, K.; De Clercq, D.; Aerts, P. Pressure distribution patterns under the feet of new walkers: The first two months of independent walking. Foot Ankle Int. 2003, 24, 444-453. [CrossRef]

12. Hallemans, A.; De Clercq, D.; Aerts, P. Changes in 3D joint dynamics during the first 5 months after the onset of independent walking: A longitudinal follow-up study. Gait Posture 2006, 24, 270-279. [CrossRef] [PubMed]

13. Ledebt, A.; van Wieringen, P.C.W.; Savelsbergh, G.J.P. Functional significance of foot rotation asymmetry in early walking. Infant Behav. Dev. 2004, 27, 163-172. [CrossRef]

14. Ivanenko, Y.P.; Dominici, N.; Lacquaniti, F. Development of independent walking in toddlers. Exerc. Sport Sci. Rev. 2007, 35, 67-73. [CrossRef] [PubMed]

15. Bisi, M.C.; Stagni, R. Evaluation of toddler different strategies during the first six-months of independent walking: A longitudinal study. Gait Posture 2015, 41, 574-579. [CrossRef] [PubMed]

16. Snapp-Childs, W.; Corbetta, D. Evidence of early strategies in learning to walk. Infancy 2009, 14, 101-116. [CrossRef]

17. Théveniau, N.; Boisgontier, M.P.; Varieras, S.; Olivier, I. The effects of clothes on independent walking in toddlers. Gait Posture 2014, 39, 659-661. [CrossRef]

18. Cohen, J. Statistical Power Analysis for the Behavioral Sciences, 2nd ed.; Lawrence Erlbaum: Hillsdale, MI, USA, 1988; ISBN 0-80580283-5. 
19. Ledebt, A. Changes in arm posture during the early acquisition of walking. Infant Behav. Dev. 2000, 23, 79-89. [CrossRef]

20. Kubo, M.; Ulrich, B. A biomechanical analysis of the "high guard" position of arms during walking in toddlers. Infant Behav. Dev. 2006, 29, 509-517. [CrossRef]

21. Van Dam, M.; Hallemans, A.; Truijen, S.; Aerts, P. A cross-sectional study about the relationship between morphology and step-time parameters in children between 15 and 36 months. Gait Posture 2010, 32, 400-404. [CrossRef] [PubMed]

22. Kingsnorth, S.; Schmuckler, M.A. Walking skill versus walking experience as a predictor of barrier crossing in toddlers. Infant Behav. Dev. 2000, 23, 331-350. [CrossRef]

23. Cho, S.H.; Park, J.M.; Kwon, O.Y. Gender differences in three dimensional gait analysis data from 98 healthy Korean adults. Clin. Biomech. 2004, 19, 145-152. [CrossRef] [PubMed]

24. Sarkar, A.; Singh, M.; Bansal, N.; Kapoor, S. Effects of obesity on balance and gait alterations in young adults. Indian J. Physiol. Pharmacol. 2011, 55, 227-233.

25. Clark, J.E.; Whitall, J.; Phillips, S.J. Human interlimb coordination: The first 6 months of independent walking. Dev. Psychobiol. 1988, 21, 445-456. [CrossRef] [PubMed]

26. Clark, J.E.; Phillips, S.J. A Longitudinal Study of Intralimb Coordination in the First Year of Independent Walking: A Dynamical Systems Analysis. Child Dev. 1993, 64, 1143-1157. [CrossRef]

27. Hallemans, A.; De Clercq, D.; Otten, B.; Aerts, P. 3D joint dynamics of walking in toddlers: A cross-sectional study spanning the first rapid development phase of walking. Gait Posture 2005, 22, 107-118. [CrossRef] [PubMed]

28. Ledebt, A.; Bril, B. Acquisition of upper body stability during walking in toddlers. Dev. Psychobiol. 2000, 36, 311-324. [CrossRef] 